\title{
La ética, nuevo objetivo de la gestión pública
}

\section{Manuel Martínez Bargueño*}

\section{Ética ¿moda o necesidad?}

La palabra "ética" ha bajado de las alturas filosóficas al nivel de la calle. Se dice que hay "falta de étican tanto en los negocios particulares como en los asuntos públicos y ello es causa de evjdente inquietud entre los ciudadanos. Se diría que de un tiempo a esta parte, la referencia ética en cualquier actividad de la vida política, social y económica es poco menos que de mención casi obligatoria.

La Ética cunde por todas partes, dice Vicente Verdú ${ }^{1}$. Muestra palpable de esta evidente preocupación creciente por la Ética son las numerosas publicaciones aparecidas en los últimos años sobre Ética en sus dimensiones social y pública.

Ante esta eclosión ética ("era de la Étican, como alguno lo ha denominado), es lícito que nos hagamos esta pregunta: dla Ética es una moda o es algo más permanente? ¿Es que la sociedad "obsesionada por la transgresión, atenta a los limites del bien y el mal tras el periodo del todo valer, se va volviendo más moral o más moralizante? (Vicente VERDÚ).

A esta pregunta: Ética ¿moda o necesidad? se han dado diversas respuestas. Hay quien, como Adela CoRTiNA, considera que la Ética está siempre de actualidad porque es una necesidad vital de los seres humanos, aunque periódicamente pueda desaparecer como objeto de atención, como el Guadiana; en el mismo sentido, dice Fernando SAVATER, que "alli donde aparecen seres bumanos en acción siempre se bace presente también la reflexión ética. Otros como Vicente VerDú consideran que "la sociedad está persiguiendo un ajuste de mayor alcance donde la revalorización de la ética animaria los sentidos del pensamiento, la acción y la convivencia.

En mi opinión, la Ética participa de ambas calificaciones: es una cuestión permanente, que se puede rastrear históricamente (por ejemplo en los libros de aEspejos de príncipes" o en memoriales dirigidos al buen Gobierno, que existen en las sociedades letradas del mundo entero) ${ }^{2}$, pero también es preciso reconocer que se trata de una cuestión de moda, impulsada por un ánimo decidido de "lucha contra la corrupción" iniciada en los países anglosajones y que en los últimos años se ha expandido a la Europa continental como un poderoso influjo.

\section{¿Una o varias éticas? Las éticas aplicadas}

¿Hay una Ética o varias éticas? Ésta es una pregunta importante. En un sentido abstracto y universal podríamos decir que la Ética es una, porque, como dice Victoria CaMPs, "unos son los derechos fundamentales y unicos los principios que establecen, por ejemplo, la dignidad absoluta de la persona bumana o la exigencia de universalidad como criterio absoluto de moralidad de las acciones.

Del mismo modo, Adela CoRTTNA considera incorrecto mantener la distinción entre eética pública" y "moral o morales privadasn, porque apor suerte o por desgracia, toda moral es pública, porque todas tienen vocación de publicidad, de bacerse públicas, de invitarse, de manifestarse. 
¿Qué sería una moral privada? ¿Aquella que me obliga a guardar una buena conducta? ¿La que se refiere a los “deberes para conmigo mismar?, (cultivar mis talentos, etc.). Pues basta esto tiene repercusiones puiblicas, porque si no me preocupo por cultivar mis talentos y soy profesora, mis alumnos acabarán siendo perjudicados. ¿Dónde se establece el límite entre mi obligación privada y mi deber público? ${ }^{3}$.

En el mismo sentido unitario de la vida humana, MACINTYRE sale al paso de la distinción establecida por Max WEBER entre vida privada y vida pública (que dio lugar al surgimiento de dos éticas contrapuestas, denominadas uética de la convicción" y "ética de la responsabilidad", objeto de un largo e ininterrumpido debate). Si partimos de la unidad de la vida de la persona, no tendría sentido que si una persona practica una virtud en su vida privada, dejara de hacerlo en el ejercicio de la vida profesional. Igualmente cualquier actividad de un individuo puede resultar dañada, incluso corrompida, por la adquisición de vicios en algún aspecto concreto de su vida. Porque, dice MaclNTYRe alas virtudes y los vicios tienen que ver con nosotros como seres bumanos, no como padres, consumidores o participes en la vida política. ${ }^{4}$.

Pero es innegable que el hombre, aunque unitario a priori, es también un "yo moderno fragmentado", debido a que la vida humana se fracciona en múltiples planos y actividades (vida familiar, social, ciudadana, comunitaria, vecinal, profesional, política, económica, cultural, etc.).

Ciertamente - como dice Adela CORTNA- las personas desean ser felices y desean serlo a través de distintas dimensiones: la dimensión familiar, por la cual son miembros de una familia; la dimensión religiosa, por la cual son miembros de una comunidad creyente; la dimensión profesional, por la cual están enroladas en una profesión (la enseñanza, la medicina, la ingenieria, etc.).

Estamos obligados, por ello, a precisar y traducir los principios ordenadores universales a directrices más concretas y es así como nacen las éticas aplicadas: la bioética, la ética empresarial, la ética de la información, la genética, la ética de la ciencia y de la técnica, la ética ecológica o la ética de las profesiones que, como señala Adela CORTINA, "monopolizan publicaciones periodísticas, se inscriben en los rótulos de las cátedras universitarias, de seminarios y de institutos de investigación; y un buen número de congresos, dedicados a diversos temas, se bonran en contar con un apartado dedicado a la ética: aspectos éticos de la investigación del genoma bumano, aspectos éticos de la ingenieria genética, aspectos éticos de cualquier investigación realizada con bumanos o con no bumanos.

Otra de las éticas aplicadas surgida en los últimos años es la llamada cética de los negocios (bussiness etbics) o ética empresarial. Fscándalos como el del caso Watergate recordaron hasta que punto la falta de credibilidad de las empresas puede resultar perjudicial para el negocio. Revistas especializadas como el Journal of Bussiness Etbics, asociaciones internacionales y nacionales como la EBEN (European Bussiness Ethics Network), empezaron a proliferar, así como cátedras de institutos de ética económica y empresarial. La idea rectora de todas estas actividades era que: para hacer negocio no sólo es preciso abandonar la ética, sino que es necesario, por el contrario, comportarse éticamente: "la ética es el mejor negocio.

Otra tercera ética aplicada importante es la ética de la información que cuenta ya con una cierta andadura, como es por ejemplo el código ético elaborado por periodistas catalanes en octubre de 1992, entendido como una "declaración de principios de la profesión periodística en Cataluña y que contenía dos partes: un pequeño preámbulo recordando los fines de la profesión (el buen desarrollo de la vida pública y la plenitud del sistema democrático) y en segundo lugar contenía doce principios que los periodistas creían necesarios seguir para alcanzar los fines de la profesión, expuestos en el preámbulo. La Federación de Asociaciones de la Prensa de España adoptó también un Código Ético el 28 de noviembre de 1993, con similares finalidades: el afán de mantener la independencia y la inquietud por recuperar la credibilidad de la profesión, puesta en tela de juicio por la proliferación de malas prácticas, tales como la difusión de noticias no contrastadas, la confusión entre hechos, interpretaciones y opiniones, la intromisión en vidas privadas, el empleo de informaciones privilegiadas en provecho propio y un largo etcétera.

Entre la ética universal y las éticas aplicadas, ¿no hay nada intermedio? Adela CORTINA ha acunado el concepto de ética cívica, como "ética de mínimos" que rescata los elementos comunes de las distintas "éticas de máximos" u ofertas propuestas de vida buena o feliz ${ }^{5}$. La ética cívica, dice, es un conjunto de valores que comparten como ciudadanos los miembros de una sociedad pluralista, sean cuales fueren sus concepciones de vida buena, sus proyectos de vida feliz. La ética cívica contiene, pues, aquellos elementos que todos los ciudadanos comparten, sea cual fuere su creencia religiosa, su adscripción familiar, su pertenencia a una profesión, a un oficio, y no contiene aquellos elementos en los que difieren. Precisamente esos elementos comunes son los que permiten a una sociedad responder conjuntamente a esos retos comunes (por ejemplo, rechazo al terrorismo).

Según Adela Cortina, el reto de nuestro tiempo está, en primer lugar, en ir tomando conciencia de los mínimos que ya compartimos, luego, dialogar sobre ello, especialmente en el terreno educativo y, en tercer lugar, trabajar con ahínco las cuestiones de ética aplicada, entendiendo por tal la aplicación de la ética civica a las distintas esferas de la vida social, para descubrir en todas las profesiones -economistas, empresarios, docentes, médicos, genetistas- los mínimos éticos en su actividad. 


\section{La ética de las profesiones}

Dice Adela CoRTiNa, a quien seguiremos fielmente en este epígrafe, que lo público no es hoy algo exclusivo de los políticos, sino que el ámbito de lo público es el lugar natural también de al menos cuatro tipos de instituciones, pertenecientes a la sociedad civil: las entidades económicas, la opinión pública, las asociaciones civicas y las actividades profesionales.

En este marco de amplia comprensión de lo público se inscribe hoy, entre otras cosas, la revitalización de una ética de las profesiones, empeñada en nuestros días en la tarea de hacer excelente la vida cotidiana.

Excelente era para el mundo griego el que destacaba por respeto a sus compañeros en el buen ejercicio de una actividad. Excelente sería abora el que compite consigo mismo para ofrecer un buen producto profesional, el que no se conforma con la mediocridad de quien unicamente aspira a eludir acusaciones legales de negligencia.

Recuerda Adela CoRTina cómo el concepto de profesión, tal como ha ido acunándose a lo largo de la historia, tiene evidentemente orígenes religiosos.

Ciertamente en el origen de lo que boy llamamos profesiones sólo se reconocian como tales tres: la de los sacerdotes, los médicos y los juristas (más tarde se reconoció como profesionales a los militares y a los marinos). Estas tres profesiones exigian vocación, ya que no todas las personas eran llamadas a ejercerlas, sino únicamente las escogidas. Pero, además, de los nuevos miembros se exigía en los tres casos que pronunciaran un juramento al ingresar, porque la actividad a la que pretendian dedicarse ya venia configurada por unas reglas $y$ valores morales que el neófito debia aceptar si pretendia ejercerla. Por otra parte, las tres profesiones tenian de algún modo un carácter sagrado, en la medida en que se dedicaban a intereses tan elevados como el cuidado del alma, del cuerpo o de la cosá pública.

Es en la modernidad cuando las profesiones empiezan a emanciparse de la esfera religiosa y a fundamentarse en una "ética autónoman. Son los reformadores protestantes los que sientan las bases para que pueda entenderse que la propia conducta moral consiste en sentir como un deber el cumplimiento de la tarea profesional en el mundo, lo que, si en un primer momento se vive como un deber religioso "para agradar a Dios", va adquiriendo paulatinamente autonomía. Tanto los profesionales liberales como los que tienen por profesión aumentar el capital sienten su tarea como una misión que deben cumplir al servicio de un interés que les trasciende. El profesional vive, todavía se dice así —consagrado" a una causa de gran trascendencia social y humana.
De ahí que el ejercicio de una profesión exija hasta nuestros días emplearse en esta causa social- sanidad, docencia, derecho, etc., que trasciende a quien la sirve, integrándose en un tipo de actividad que ya tiene sus rasgos específicos.

Pero, prescindiendo de los orígenes, ¿qué es hoy una profesión? Una profesión -dice Adela CORTINA- es, en principio, - una actividad bumana social, un producto de la acción de personas concretas mediante la cual se presta un servicio específico a la sociedad y se presta de forma institucionalizada. La medicina, la docencia, o la información son en primer lugar actividades realizadas por personas en el marco de una institución que "da cuerpo" a todas esas actividades.

Una profesión es un tipo de actividad social a la que se han atribuido desde Max WEBER una serie de rasgos definidores:

A) En lo que respecta al tipo de servicio:

- el servicio ha de ser único y por eso los profesionales reclaman el derecho de prestarlo a la sociedad en exclusiva, considerando como aintruso" a cualquiera que desee ejercerlo desde fuera;

- las prestaciones que de él puedan obtenerse han de estar claramente definidas de modo que el público sepa a que atenerse con respecto a esos profesionales, es decir, qué puede esperar de ellos y qué puede exigirles;

Transmitir conocimientos y educar en la autonomía es el bien de la docencia; ampliar la información de los ciudadanos y proporcionarles opiniones diversas es el de la actividad informativa; prevenir la enfermedad, cuidar y curar es el bien de las profesiones sanitarias; trabajar por una convivencia más justa debería ser la meta de los juristas en sus diferentes dedicaciones;

- ha de tratarse de una tarea indispensable, es decir, de un tipo de servicio del que una sociedad no puede prescindir sin perder una dosis inrrenunciable de salud (actividad sanitaria), formación (actividad docente), organización de la convivencia (actividad jurídica), información (actividad informativa), etc.

B) La profesión se considera como una suerte de vocación y de misión, lo cual no significa que alguien se sienta llamado a ellas desde la infancia, sino que cada profesión exige contar con unas aptitudes determinadas para su ejercicio y con un peculiar interés por la meta que esa actividad concreta persigue. Por eso se espera del profesional que se entregue a su profesión e invierta parte de su tiempo de ocio, preparándose para cumplir bien esta tarea que le sea encomendada. A diferencia de 
las ocupaciones y oficios, que pueden tener un horario claramente delimitado, el profesional considera indispensable tener una preparación lo más actualizada posible para poder ejercer bien su tarea; de ahí que dedique también parte de su tiempo de ocio a adquirir esa preparación.

C) Ejercen la profesión un conjunto determinado de personas a las que se denomina profesionales, quienes lo hacen de forma estable obtienen a través de ella su medio de vida y se consideran entre sí colegas.

D) Los profesionales forman parte de un colectivo que obtiene, o trata de obtener, un control monopolítico sobre el ejercicio de la profesión (lucha contra el intrusismo).

E) Se accede al ejercicio de la profesión a través de un largo proceso de capacitación teórica y práctica. Estos estudios deben ser específicos, recibir a su término algún documento oficial acreditativo (diplomatura, licenciatura) y ser sólo dominado por los miembros de esa profesión determinada.

Dice Adela Cortina que éste es uno de los grandes problemas en profesiones como periodismo, en las que resulta sumamente discutibles que quien ha estudiado la carrera de Ciencias de la Información esté más preparado para informar y opinar que algunas personas cultas, dotadas de una pluma ágil. Y también en ámbitos como la enfermería, donde resulta dificil determinar el cuerpo de saber técnico que sus profesionales poseen en exclusiva cuando parece que el médico posee este tipo de saber en mayor modo. Determinar ese saber específico es hoy uno de los retos de la enfermería.

F) Los profesionales reclaman un ámbito de autonomía en el ejercicio de su profesión. El profesional (médico, abogado, periodista) se presenta ante la sociedad como un experto en el saber correspondiente y por ello, ante eventuales protestas y quejas de sus clientes, exige no sólo ser parte sino juez a la hora de determinar qué forma de ejercer la profesión es la correcta y qué formas de ejercerla son desviadas (ello explicaría la existencia de los antiguos Tribunales de Honor, prohibidos luego por la Constitución).

Tradicionalmente, los colegios profesionales promulgan códigos de la profesión con la intención de autorregularse y resolver los posibles conflictos antes de tener que acceder a los juzgados. Lo positivo de estos códigos deontológicos -dice Adela CORTINA- es que los profesionales tomen conciencia de las exigencias de su profesión y sean los primeros en querer dignificarla; lo negativo es que este modo de proceder lo sea por motivos corporativistas en la medida que el cuerpo profesional pretende cerrar filas e impedir cualquier juicio externo.
Conviene advertir que la deontología no es lo mismo que la ética, y por consiguiente los códigos deontológicos no deben confundirse con los códigos éticos ${ }^{6}$.

Explica Adela Cortina, siguiendo a MaCINTYRe, que con las distintas actividades se pueden alcanzar unos bienes externos, que son comunes a todas las profesiones, tales como el dinero, el prestigio o el poder social. Esos bienes se llaman externos porque pueden lograrse, en mayor o menor medida, con cualquier actividad sea la sanidad, la información, el deporte, la investigación, la docencia o la jurisprudencia, de forma que no especifica a ninguno de ellos en concreto.

Pero cuando alguien ingresa en una actividad social -recordemos que una profesión es una actividad social- se encuentra con que esa actividad tiene unos fines, que esa persona no inventa, sino que le vienen dados y constituyen el bien interno de esa actividad que es la meta de esa profesión (podríamos decir que el bien interno de la sanidad es el bien del paciente; el de la empresa la satisfacción de necesidades humanas con calidad; el de la docencia, la trasmisión de la cultura y la formación de personas críticas, etc).

No podemos inventar los fines de las actividades profesionales -dice Adela CoRTina - porque ya proceden de una tradición que conviene conocer a fondo, estudiando su historia. La tarea de quien ingresa en una profesión no consiste, pues, en idear metas totalmente nuevas, sino en incorporarse a una tarea de siglos o de décadas - a una tradición profesional- y en integrarse en una comunidad de colegas que persiguen idénticas metas.

Alcanzar los bienes internos propios de una profesión exige a quienes participan en ella, desarrollar determinados hábitos, que Adela CORTINA, denomina "virtudes" expresión que conviene entender en el sentido que tenía en la Grecia clásica como areté, como excelencia del carácter. El virtuoso - dice esta autora- "es el que pretende alcanzar en ella la excelencia y buye de la mediocridad, de la medianía. Ello no significa una carrera hacia la competencia de unos con otros sino en que cada cual se esfuerce, en la medida de sus posibilidades, para alcanzar ese grado de excelencia en aquellas aptitudes que son requeridas para alcanzar el bien interno de la práctica profesional.

Práctica profesional que, también hay que decir, va evolucionando con el tiempo, en la medida que va evolucionando la conciencia moral de la sociedad en el sentido de que las personas reclaman un mayor respeto a su autonomia, exigen que se respeten sus derechos, piden que se les deje participar en las decisiones que les afectan. Pacientes y consumidores, ciudadanos y lectores, presentan paulatinamente tales exigencias, pero también quienes trabajan en la profesión: enfermeras, médicos, proveedores. Con ninguno deben realizarse prácticas bumillantes, a ninguno debe tratarse sin respeto. Esta evolución de la concien- 
cia moral, exige que los profesionales derrochen capacidad creativa, inventiva rigurosa, para alcanzar la meta de su profesión de una forma acorde con la conciencia moral de su tiempo.

¿Es compatible la consecución de los bienes externos con el logro de los bienes internos? Obviamente, dice Adela CoRTiNA, no existe ningún problema en que un profesional, además de intentar alcanzar los bienes internos de su profesión, perciba a través de ella unos ingresos, logre un poder social y se gane un prestigio si es excelente. Lo que, en cambio, desvirtúa cualquier profesión es el hecho de que quienes la ejercen cambien los bienes internos por los externos: olviden la meta por la que la profesión cobra sentido y legitimidad social y busquen únicamente dinero, prestigio o poder. En este caso, las profesiones se corrompen de forma inevitable.

¿Cómo se puede alcanzar la excelencia profesional? Diego Gracia recuerda que al profesional uvirtuoso" le es inherente ejercer la virtud física, que consiste en ser competente en las habilidades propias de la profesión, y la virtud moral, que se predispone a emplear siempre esas habilidades en el buen sentido que exige la profesión para prestar su servicio a la sociedad. El profesional debe, por tanto, aspirar a la excelencia física y a la excelencia moral, ya que un buen profesional no es simplemente el que cumple las normas legales vigentes de forma que no se le puede acusar de incurrir en conductas negligentes. No basta para adquirir la perfección con cumplir unos minimos de permanencia en el centro correspondiente y de atención a la clientela, trátese de alumnos, pacientes, o de otra suerte de realización de una actividad profesional. La ética de la profesión pide mucho más: exige de los profesionales aspirar a la excelencia. Entre otras razones porque el compromiso de los profesionales no es el que les liga con la organización, sino con las personas concretas, con las personas de carne y hueso cuyo beneficio da sentido a cualquier actividad o institución social. Adela CORTINa se muestra partidaria de lo que ella llama unniversalizar la aristocracian, introducir en la vida corriente, en la práctica de las profesiones, la aspiración a la excelencia.

En un sentido parecido al expresado por Adela CoRTINA se manifiesta RodríguEz-ARANA, para quien las profesiones, entendidas como hábitos de conducta en aplicaciones de carácter técnico y dedicación vocacional de las personas, suponen un compromiso riguroso con uno mismo y con la sociedad a la que se pertenece. Su trascendencia rebasa la conciencia personal y las repercusiones sobre los demás -quienes demandan o necesitan de los servicios profesionales, sus familiares, los colegas de ejercicio profesional e, incluso, la afectación de los llamados aintereses difusos, - revistiendo multitud de aspectos de señalada importancia. Esto es lo que explica, junto con otros factores, la proliferación de los denominados "códigos deontológicosn.
Las regulaciones deontológicas persiguen, dentro del marco de la Ética profesional, unos objetivos concretos y limitados: el establecimiento de normas y pautas de conducta profesional que tiendan a garantizar una actuación honesta en interés de quienes demandan los servicios profesionales y de la propia colectividad o corporación profesional. La deontología profesional, ámbito propio donde se amonizan los principios de carácter permanente moral con las reglas que disciplinan la actuación profesional, ha de tener en cuenta, dice RODRíGUEZ-ARANA, materiales y formulaciones positivas de carácter jurídico o adoptadas convencionalmente, con independencia de su carácter vinculante.

\section{La ética en la Administración Pública}

Una de las éticas profesionales a la que antes hacíamos referencia es la de aquellos profesionales que trabajan en las Administraciones Públicas. La Administración Pública, recuerda RodRíguez-ARANa, es una organización compuesta de personas que gestionan intereses generales (art. $103 \mathrm{CE}$ ). La idea de servicio de los intereses generales debe presidir la actuación de cualquiera que realiza una función pública. Autoridad o funcionario público, debe hacer siempre lo que sea mejor para los intereses públicos (González Pérez). El personal al servicio de las Administraciones Públicas - sea funcionario, estatutario o laborallleva a cabo trabajos orientados a la satisfacción de las necesidades colectivas; de ahí que las consideraciones éticas constituyen algo consustancial con la actividad de quienes forman parte de las Administraciones Públicas.

La Administración Pública se puede considerar al menos desde tres perspectivas:

- Como una actividad social, que persigue un bien interno (el interés público), a través de unas determinadas técnicas que son propias de una profesión, la de funcionario público, o más exactamente, la de los distintos colectivos - Cuerpos y Escalas- de los que se compone la Función Pública.

Por tanto, quienes ingresan - por los móviles que sean- (por buscarse un trabajo seguro apara toda la vidan; por vocación de servicio público, por necesidad, por azar) en la Administración Pública, se ven obligados a asumir ese bien interno, lo quieran o no, en cuanto se avienen a participar en ella.

- Como una organización, habida cuenta de que una organización es un grupo humano, compuesto por especialistas que trabajan juntos en una tarea común. La función de 
la Administración Pública como organización parece clara - dice Adela CORTINA- y consiste en el servicio a los ciudadanos. Rodríguez-Arana señala que la idea de servicio público es el fundamento de la Ética, por eso el trabajo en el sector público fue identificado desde sus orígenes con la honradez, la laboriosidad, la eficacia, la transparencia y otros muchos valores que hicieron del trabajo en el sector público una auténtica tarea de la que la sociedad espera frutos de calidad.

Porque la Administración es una organización, precisa - dice Adela CORTINA - de una clara cultura organizativa, sólido grupo de creencias sobre las que se asienta la política y acciones y porque las organizaciones son comunidades morales, que interactúan y desarrollan relaciones humanas, resulta esencial en este grupo humano las buenas relaciones, las relaciones de cooperación entre quienes trabajan en ella y los ciudadanos.

Desde este punto de vista, los valores específicos de una Ética de la Función Pública serían, entre otros, la profesionalidad, la eficiencia, la eficacia, la calidad en el producto final, la atención y el servicio al ciudadano, la objetividad, la transparencia, la imparcialidad y la sensibilidad suficiente para percatarse de que el ciudadano es el centro de referencia de toda su actividad, quien da sentido a su existencia. Rodríguez-ARAna afirma que la Administración Pública exige hoy también, además de los anteriores, honradez y honestidad, trabajo bien hecho, gastos razonables, consecución de objetivos, rendición de cuentas, configurar, en suma, un entorno laboral de verdadera humanización.

- Como una institución social, la Administración Pública es también uno de los pilares básicos del tejido social, un componente esencial de la estructura básica de la sociedad que tiene unas metas y unos fines sociales. Joan Prats dice que como institución la función pública es el conjunto de valores, principios y normas -formales e informales - que plantean los aspectos de la vida funcionarial considerados socialmente relevantes.

Desde esta perspectiva, la Administración necesita también de normas de comportamiento que descansen en los valores de la institución. Y asumir una postura ética resulta también eficiente para la institución, porque la ética reduce costes de coordinación externos e internos, posibilita la identificación con la institución y una motivación suficiente.

Quienes trabajan en la Administración Pública - funcionarios, empleados públicos, o como quiera llamárseles - se pueden enfrentar con serios problemas morales - conflictos o dilemas éticos, los llaman los anglosajones-. Agustín IzQuierdo los clasifica en conflictos internos cuyo escenario es la conciencia individual, en la que inclinaciones de signo contrario tratan de imponerse una sobre otras y antagonismos que se desarrollan con otros individuos dentro de la organización que, a su vez, pueden estar en posición subordinada o superior con respecto al individuo en cuestión. He aquí un inventario de ellos:

- La "esquizofrenia" que puede suceder, en ocasiones, por tener que atender a la vez los requerimientos del Gobierno y los de los ciudadanos, por tener que servir a veces a dos señores que piden lo mismo (Arlequín, servidor de dos amos).

- Distinguir lo que es discrecional de lo que es arbitrario. En el mundo de la Función Pública frecuentemente las decisiones son discrecionales, pero resulta difícil distinguir entre lo discrecional y lo arbitrario, cuando no están claras las razones que avalan una decisión.

La discrecionalidad puede darse, incluso, cuando las órdenes carecen de ambigüedad pues la clase de respuesta puede ser muy variada: desde una acción vigorosa e imaginativa a una retardada y llena de titubeos. Lo que debe quedar siempre claro es que las decisiones discrecionales deben estar movidas a su vez por el interés público y no por el propio interés del funcionario o por tendencias ajenas a lo público.

- La tentación de utilizar el cargo público en beneficio privado, propio o de otras personas. En esto consiste previamente la corrupción, en la utilización de potestades públicas para intereses particulares, cualquiera que sea la forma de manifestarse, sea en beneficio propio o de un tercero, sea por razón de autoridad o por dinero o por otros beneficios (SABÁN GODOY) ${ }^{7}$. Ciertamente, como recuerda GarCía de ENTERRÍa, la comupción es un fenómeno que viene de lejos. SÉneCA escribió hace ya muchos siglos que la corrupción es un vicio de los hombres, no de los tiempos. Pero es un hecho cierto, sin duda, que la corrupción ha cobrado nuevos aspectos en nuestro tiempo y una penetración bastante más extensa. Politólogos y analistas sociales estiman que, lejos de prever su control y paulatina desaparición, la corrupción se incrementará en el futuro, facilitada por la mundialización de la economía y el desarrollo tecnológico. "Actualmente, la pérdida de la ética y la prosperidad económica ban convertido a la compción en patológica e inaceptablo. (Giovanni SARTORI).

De la corrupción, sobre la que cada vez aparecen más libros publicados ${ }^{8}$, sólo diremos dos cosas: primero, que en España este fenómeno se encuentra más frecuentemente en los niveles alto y medio de la clase política que en la estrictamente hurocrática (G.ARCIA DE ENTERRía); 
segundo, que, aunque determinadas formas de comupción, las más graves, pueden ser constitutivas de conductas encajables en algún tipo penal o disciplinario (cohecho, malversación, prevaricación, tráfico de influencias) otras muchas son simplemente muestras de una tolerancia social, por ejemplo, las infracciones menores de tráfico o la práctica de las erecomendaciones", que están muy arraigadas en la conciencia social y por ello resultan difícilmente erradicables. Con todo, citamos a Rodríguez-ARANA, la corrupción más grave que acecha a la Administración es el ambiente de incompetencia o mediocridad de quien no es consciente del elevado valor que tiene el servicio público, cualquiera que sea el puesto que se ocupe en la maquinaria administrativa.

- Otros problemas éticos se derivarían de la asimetría entre las relaciones entre la Administración y los administrados. En el caso de la Administración, dice Adela Cortina, esta asimetría es casi total "el ciudadano se siente un pigmeo enfrentado con un gigante. La desigualdad es la norma, "desde el momento mismo en que el administrado se pone en contacto con la Administración Pública y se encuentra con la ventanilla, dice GONZÁLEZ PÉREZ, quien contrapone este trato con el que da la Administración a los administrados aprivilegiados ${ }^{\text {s. }}$

De todos estos dilemas pueden derivarse diversos estados y actitudes. Por ejemplo, si no se comprenden bien los elementos en conflicto y no se es capaz de llegar a soluciones, es posible que el sentido moral acabe deteriorándose y se pierda con ello la capacidad de tomar decisiones, al tiempo que disminuye el sentido de la responsabilidad, evitando el sujeto cualquier contacto con situaciones conflictivas que puedan requerir decisiones difíciles. Otras veces lo que se produce es un mecanismo de transferencia de la responsabilidad al superior "no obstante, V.I. decidirá, como se decía en los antiguos formularios) o bien una parcelación de ésta al terreno interno, por el que la persona se siente responsable sólo ante la autoridad que le dirige, pero no siente responsabilidad alguna por el contenido de las acciones que la autoridad prescribe.

El exceso de burocratización, el procedimentalismo, la falta de transparencia, la convicción de que el acceso a los cargos públicos tiene poco que ver con el mérito y la capacidad son otros tantos obstáculos para el despliegue de la Ética en la Administración Pública.

¿Cómo sería posible ir cambiando estos hábitos y desarrollar conductas adecuadas a los bienes y valores antes mencionados, como propios de una Administración Pública en el pleno sentido de la palabra?
¿Cómo sería posible que la persona se sintiera responsable de su trabajo y poseedora de una ética autónoma que pueda hacer nacer de él un sentido de responsabilidad profesional?

Antes de dar respuesta a este interrogante, debemos hacer un repaso del panorama internacional comparado.

\section{Ética pública. Un panorama comparado}

Hace apenas quince años, la cuestión ética aplicada a las organizaciones públicas era un tema casi inédito. Es sólo a partir de 1978 cuando comienza la preocupación por la ética en la Administración Pública, como expresión de un movimiento convergente en el que toman parte Gobiernos y opinión pública.

En Estados Unidos, uno de los países claves en la conceptualización de la Ética Pública, esta preocupación surge, como respuesta a un problema de management, para obtener una mayor eficiencia y credibilidad de la función pública, muy deteriorada a partir del escandalo Watergate y por las críticas al funcionariado de la Administración Reagan (los funcionarios son el problema). Esta preocupación pública, compartida académicamente y con suficiente respaldo popular, impulsará las reformas Carter: Civil Service Reform Act, Etbics in Government Act e Inspectorate General Act, todas ellas de 1978.

En la década de los 80 se puede empezar a hablar de un cierto boom del tema ético en la Administración Pública. Si en 1978 sólo se había publicado un único libro sobre la materia (RoHr. Etbics for bureaucrauts. New York. Marcel Dekker, 1978), a partir de entonces la ética aplicada a las organizaciones públicas comienza a ser una cuestión tópica en las reuniones y conferencias internacionales y son más abundantes las investigaciones y publicaciones sobre la materia, especialmente en los países anglosajones.

En 1984, la American Society for Public Administration (ASPA) aprobó un código ético creado para elevar la práctica y los valores éticos de sus miembros. Y a finales de los 80 , la $\mathrm{Na}$ tional Association of Schools of Public Affairs and Administration (NASPAA) incorporó una redacción en la normativa sobre sus curricula exigiendo programas de Administración Pública que "mejorasen los valores morales, el conocimiento y las babilidades de los estudiantes para que estos actuasen de forma ética y eficaz.

En la década de los 90 florecen los estudios e investigaciones aplicadas sobre Ética y Administración Pública. Destacaremos como hitos más importantes de esta "revolución ética" la celebración de la Conferencia Internacional sobre Ética en el 
Gobierno, convocada por la Oficina Americana de Ética Gubernamental y la Agencia Americana de Información, en noviembre de 1994 en Washington y a la que asistieron más de 100 participantes de 53 paises de los cinco continentes?

Esta reunión se caracterizó por la cantidad de países y culturas representadas, el predominio de funcionarios responsables de la dirección de programas de ética en sus respectivos países y se centró principalmente en la propuesta de que la democracia y la economía de mercado dependen de la confianza de la opinión pública en la integridad de las instituciones gubernamentales y los funcionarios públicos.

En relación con el fenómeno, vinculado a la Ética Pública, de la "lucha contra la corrupción", señalaremos la labor de las Naciones Unidas, tanto de la Asamblea General como del Consejo Económico y Social (ECOSOC). En 1996, la Asamblea General adoptó la Resolución 51/59, de 12 de diciembre, por la que se aprobó el Código Internacional de Conducta para los titulares de cargos públicos, así como la Resolución 51/1995, de 16 de diciembre, en la que se aprobó la Declaración de las $\mathrm{Na}$ ciones Unidas contra la corrupción y el soborno en las transacciones de comercio.

Por su parte, el Consejo de Organización de la OCDE adoptó en 1997 una recomendación sobre la lucha contra la corrupción en las transacciones económicas internacionales y en 1998 aprobó un Convenio contra la corrupción de agentes públicos extranjeros en las transacciones comerciales internacionales.

Otras organizaciones, especialmente financieras, como el Fondo Monetario Internacional, el Banco Mundial y el Banco Interamericano de Desarrollo, dentro de sus programas de reforma y modernización del Estado, han realizado estudios y dedicado esfuerzos al tema de la corrupción.

En el ámbito iberoamericano, citaremos la Convención Internacional contra la Corrupción, aprobada en la reunión de la Conferencia Especializada de la Organización de Estados Americanos celebrada en Caracas en marzo de 1996, que entró en vigor el 6 de marzo de 1997, así como la aprobación de un plan de acción contra la corrupción, decidida en la reunión del Foro Iberoamericano sobre el combate a la corrupción, auspiciada por el Centro Latinoamericano de Administración para el Desarrollo (CLAD) y la Agencia Española de Cooperación Iberoamericana y que se celebró en Santa Cruz de Bolivia, en junio de 1998.

En el ámbito europeo, tanto la Unión Europea como el Consejo de Europa han tenido un especial interés en la lucha contra la corrupción. Por ejemplo, el Consejo de Europa, a través del Grupo Multidisciplinario sobre Comupción, ha aprobado un Programa de Acción de cinco años y, en la actualidad, se encuentra considerando un proyecto de convención europea contra la corrupción.
A nivel nacional, como subraya Rodríguez-AraNa sla ética pública ba pasado boy a ocupar un lugar destacado en las reflexiones sobre la reforma y la modemización administrativa, si bien no existe unanimidad en cuanto a normas que definan el comportamiento de los funcionarios y las prácticas difieren de unos paises a otrosi.

El enfoque más frecuente consiste en vincular la Ética del servicio público con la transparencia de la Administración y, en tal sentido, estudios detallados realizados en distintos países demuestran hasta que punto la ética burocrática está condicionada en gran medida por factores históricos, determinados por la cultura pública del país afectado.

Es aleccionador comprobar cómo hasta hace pocos años transparencia y ética se consideraban como temas marginales de la reforma administrativa, alejados del debate intelectual, ausentes de la retórica política y como "arrojados por la puerta, ban vuelto a entrar por la ventana. (O'ToOLE, 1993).

Actualmente, la preocupación por las cuestiones éticas es patente en todos los países de la OCDE. En 1996, esta Organización publicó el estudio, La ética en el servicio priblico: cuestiones y prácticas actuales, sobre la base de las experiencias previas habidas en nueve países: Austria, Finlandia, Méjico, Países Bajos, Nueva Zelanda, Noruega, Portugal, Reino Unido y Estados Unidos.

En todos estos países los funcionarios ejercen sus funciones en un contexto de cambio. Están sujetos a una vigilancia estrecha de parte del público y deben satisfacer demandas crecientes de los ciudadanos, cuando, al mismo tiempo, los recursos de los que disponen son cada vez más limitados. Tienen que asumir nuevas funciones y responsabilidades suplementarias por diferentes razones, lo que comporta un mayor poder de apreciación discrecional en materia de gestión y nuevas formas de responsabilidad. La forma de llevar modernamente los asuntos de la Administración requiere adoptar nuevos modelos de conducta basados en planes de eficacia y de eficiencia. No se trata de que los cambios hayan provocado un aumento de malas conductas o de comportamientos contrarios a la ética, sino que estos cambios pueden colocar a los funcionarios en situaciones que ocasionen conflictos de intereses o de objetivos para las cuales no disponen sino de unos pocos principios rectores sobre la manera que deben actuar. Pudiera existir una distancia cada vez mayor entre los valores y los sistemas tradicionales que rigen la conducta de los funcionarios y en los nuevos papeles que les han sido asignados en un sector público en plena transformación.

De la lectura del informe se deduce, con más o menos matices, que hay un alto grado de coincidencia en la identificación de los valores esenciales del servicio público que incluyen junto 
con antiguos valores como la integridad, la imparcialidad y la responsabilidad, otros valores nuevos asociados con las reformas en materia de gestión pública tales como la eficiencia, la eficacia y el servicio al cliente. También es importante consignar cómo en muchos países hay la convicción de que la inculcación de estos valores y su interiorización en las conciencias de los funcionarios públicos es una alternativa preferente a intentar mantener y aplicar principios éticos mediante normas y directivas. El factor clave es cómo aplicar estos valores comunales al trabajo diario de los funcionarios.

Para ello, los Gobiernos de estos países utilizan numerosos instrumentos y procedimientos que tratan de evitar conductas indeseables y de incentivar las buenas conductas. A este conjunto de instrumentos y procedimientos lo llama la OCDE una infraestructura étican, que incorpora tanto elementos normativos como estructurales y los divide en categorías según la función principal que desempeña: control, guía o gestión.

El primer elemento es el compromiso político, spiedra angular de la infraestructura étican. Sin mensajes claves por parte de los líderes políticos, las iniciativas para mejorar el nivel de la ética en el sector público caerán en el vacío. Así, en los países de la OCDE se han patrocinado tentativas para favorecer la Ética en el sector público, por ejemplo la Comisión Nolan en el Reino Unido (1994) o la Comisión Presidencial de Integridad y Eficiencia en los Estados Unidos (1991). En todas estas medidas se destaca la importancia del ejemplo que han de ofrecer los líderes en cuanto a modelos de conducta.

El segundo elemento es el marco legal efectivo, conjunto de leyes y reglamentos que se refieren a conductas de los funcionarios. Este marco - dice la OCDE - debería ser claro y consistente y no deberían anadirse nuevas normas que incrementen el volumen y la complejidad de la legislación; cuando de lo que se trata sobre todo es de modernizarla. En opinión de algunos, la Ética no puede ser objeto de legislación. Como mucho, la legislación puede definir los límites (inferiores) de las conductas aceptables. Tiende a fomentar un mínimo de obediencia porque la legislación está más concebida para penalizar comportamientos indeseables que para estimular una buena conducta.

En tercer lugar, pueden existir mecanismos de exigibilidad o responsabilidad eficaces para controlar la consecución de objetivos y la observancia de procedimientos y que van desde la exigencia de informes parlamentarios y procesos de auditoría hasta mecanismos internos, como la exigencia de actos por escrito, compensación por daños, etc. Teóricamente, los mecanismos de responsabilidad pueden estimular un comportamiento ético convirtiendo las actividades poco éticas en difíciles de acometer y fáciles de detectar.

Un cuarto elemento serían los códigos de conducta, uno de los más debatidos. La OCDE ha detectado numerosas preocupa- ciones en relación con los códigos de conducta, de los que disponen varios países. Entre las tachas que se les achacan es que son demasiado específicos o demasiado generales, imposibles de llevar a la práctica, no utilizados, desconocidos o incluso considerados un insulto para los empleados diligentes. Hay, además, una gran variedad de códigos: los que pueden tener fuerza legal $-\mathrm{y}$ son equivalentes a un régimen disciplinario, como en Italia - o los que contienen simplemente el enunciado de un conjunto de directrices y una declaración de valores, los que se pueden aplicar al servicio público en su totalidad, a una parte específica o a un departamento y oficina concreto. Con todo, lo principal de las preocupaciones sobre los códigos es que unas declaraciones relativamente simples de normas y aspiraciones no son capaces de tratar todos los complicados asuntos éticos a los que se enfrentan los funcionarios públicos. Por eso, dice la OCDE que los códigos pueden ser un marco útil de referencia pero que no se debe esperar de ellos que lleven el peso principal de la Administración de la ética. En el mejor caso constituyen un acompanamiento útil de las otras herramientas; en el peor se pueden encontrar con la indiferencia, cuando no la hostilidad de los empleados ${ }^{10}$.

Un quinto elemento sería la socialización profesional, proceso por el cual los funcionarios aprenden e inculcan valores y principios éticos. Los mecanismos clave de socialización son la educación y los programas de formación y la existencia de modelos ejemplares en los niveles superiores.

La formación en ética - dice RODRíGUEz-ARANA- es un tema clave en el desarrollo futuro de las Administraciones Públicas. La incorporación de programas de Ética en las Escuelas e Institutos de Administración Pública debe posibilitar una mejora sustancial en temas tan importantes como la dirección administrativa, las competencias de los gestores públicos, la conducción de las políicas públicas, de dirección del personal, el clima de trabajo o la responsabilidad de los funcionarios.

Además, los programas de Ética Pública están llamados a concretar los valores del Servicio Público. Sobre esta idea del Servicio Público han de girar los problemas de Ética. La Ética Pública, dice Rodríguez-ARANA, debe propiciar la reflexión sobre el servicio público.

"La enseñanza de la Ética para funcionarios, en mi opinión, debe plantearse antes de la entrada en la función puiblica y después. Antes porque a los poderes públicos les conviene asegurar un "minimum" de contenidos éticos en las personas que acceden a la Administración Pública. Y después porque debe reconocerse que la formación no termina nunca y que es necesario explicar las lecciones de Ética de acuerdo con las nuevas y variadas problemáticas que bistóricamente plantea la discrecionalidad administrativa. 
La cuestión problemática sobre la enseñanza de la Ética está más bien en el tipo de docencia a impartir, en el método y en el profesorado. Dice Rodríguez-ARana que la Ética como ciencia de lo moralmente adecuado al servicio público debe explicarse a todos los funcionarios públicos, a través de un programa eminentemente práctico dirigido por hombres del servicio público que se hayan caracterizado por una trayectoria intachable y que apunten condiciones docentes.

En cuanto al método, el profesor KernaGHan, canadiense, dice que un módulo de Ética debería contener dos clases principales de materiales: literatura sobre conducta ética en general y sobre áreas particulares así como casos relacionados con áreas específicas de comportamiento auténtico. Además, se debería añadir una bibliografía seleccionada para quienes deseen tener lecturas adicionales. El módulo debería incluir una explicación de la preparación y discusión de casos, mediante los cuales los diversos integrantes del grupo aprendan analizando una descripción de situaciones administrativas actuales y de decisiones.

A través de planes y programas bien diseñados de Ética Pública se puede conseguir que los funcionarios adopten una postura creativa en su trabajo, independientemente del lugar que ocupen, de innovación, con mentalidad abierta y perspectiva de futuro.

El liderazgo sería otro de los elementos̀ importantes para la modelación de comportamientos éticos de los funcionarios públicos. No en vano, lo incluye, en séptimo lugar, el Informe Nolan, dentro de los llamados asiete principios de la vida pública". Los modelos ejemplares son una fuerza mucho más positiva que la retórica y las reglas. Si se percibe que los jefes están insuficientemente motivados en relación al interés por la ética y los valores, no es probable -dice la OCDE- que los funcionarios de nivel inferior presten mucha atención a dichos valores.

El sexto elemento serían las condiciones de trabajo en el servicio público, especialmente la política de recursos humanos que lleve a cabo el organismo. En palabras de la OCDE, "si los funcionarios públicos se sienten que están mal pagados, que trabajan en exceso y en condiciones inseguras o si los conflictos laborales son frecuentes, probablemente estarán menos dispuestos a adoptar iniciativas para la mejora del rendimiento incluso en el aspecto ético. Por el contrario, un exceso de seguridad puede dar como resultado complacencia.

Los países de la OCDE ponen el énfasis en los distintos elementos de esta infraestructura ética. Cada país debe definir su ipropia política sobre la base del lugar del que parten y al lugar donde quieren dirigirse con sus sistemas de Función Pública. El equilibrio entre los diferentes componentes de esta infraestructura ética dependerá de la tradición cultural, política y administrativa y de la orientación que quiere darse a su actividad para promover un comportamiento ético en el sector público. Inde- pendientemente de ello, una conducta apropiada y ética de los funcionarios públicos es un imperativo cada vez más poderoso. De aquí que los países de la OCDE hayan dado prioridad, en sus programas de reforma de la Gestión Pública, a una cuarta "En que viene a añadirse a las tres anteriores (Economía, Eficacia y Eficiencia) y que es la "En de la Ética.

Por último, conviene reseñar que el 22 de abril de 1998, el Consejo de la OCDE aprobó un conjunto de principios adecuados para favorecer la gestión de la ética en el servicio público y recomendó a los países miembros que adopten disposiciones encaminadas a velar por el buen funcionamiento de las instituciones y de los sistemas destinados a fomentar un comportamiento ético en el servicio público.

\section{El Informe Nolan}

De todos los documentos recientemente aparecidos en los países de la OCDE, relativos a la Ética Pública, sin duda alguna el más famoso de todos es el First Report of the Committee on Standars in Public Life 1995, (Primer Informe de la Comisión sobre Normas de Conducta en la vida pública) 1995, conocido como primer Informe Nolan, por ser éste el nombre de la autoridad que presidió la Comisión ".

Este informe es bastante conocido en España, por haberse referido a él un importante sector doctrinal ${ }^{12}$ y además por la visita que el propio Lord Nolan realizó a nuestro país en la primavera de 1997, para inaugurar unas Jornadas sobre Ética Pública organizadas por el INAP.

La preocupación de la opinión pública sobre las cuestiones relativas al comportamiento de los hombres públicos (parlamentarios, políticos, altos funcionarios), que "trascendiendo a la sociedad, crearon un clima generalizado de degeneración ética en el que los escándalos de tipo económico, politico y sexual aparecen mezclados, llevó al Primer Ministro a crear en octubre de 1994 la Comisión de Normas de Conducta (Standars) en la vida pública con el siguiente cometido: examinar las inquietudes actuales relativas a las normas de conducta de todas las personas que desempenan cargos públicos y recomendar los cambios necesarios para asegurar los más altos niveles de corrección en la vida pública.

La Comisión, formada por doce personas (ex-ministros, altos funcionarios, hombres de negocio, intelectuales) y presidida por Lord Nolan, prestigioso jurista y juez de profesión, fue requerida a entregar un primer informe en seis meses, por lo que tuvo que concentrarse en tres áreas de interés fundamental: Parlamento, Gobierno (ministros y funcionarios) y otros orga- 
nismos públicos (quangos, cuerpos ejecutivos y entidades del Servicio Nacional de Salud).

El Informe tiene, por así decirlo, una parte de investigación y otra de objetivos hacia el futuro. Más que corrupción en la vida pública, lo que el Informe Nolan detecta es incertidumbre y ambigüedad, los miembros de la Función Püblica no tienen siempre claro cuál es el limite para una conducta aceptable en su actuación. Por eso, se propone como objetivos: aportar claridad y orientación alli donde se presenta la incertidumbre de un lado, y, de otro, restablecer la confianza en el ciudadano en el actuar de la Administración.

Para ello, el Informe establece una serie de valores que deben ser tenidos en cuenta por la Administración Pública a la hora de gestionar los servicios públicos. Son los denominados asiete principios de la vida públican:

- Altruismo (capacidad de asumir el interés público como objetivo de la actuación personal).

- Integridad.

- Objetividad.

- Responsabilidad.

- Transparencia.

- Honestidad.

- Liderazgo (o capacidad de decisión).

Son principios, dice el propio Lord Nolan, usencillos, fácilmente comprensibles por cualquiera y aplicables a cualquier organización que desempeñe servicios públicos. ${ }^{13}$.

Estos siete principios, que son un intento de plasmar los valores universales del servicio público en palabras simples, deben ser reforzados con tres requerimientos prácticos.

- Que cada organización cuente con un código de conducta establecido por ella misma. Dice Lord Nolan: "la clave para mantener las normas éticas en cualquier organización está en crear dichas normas mediante el gobierno diario de la misma y en las actitudes diarias de sus componentes.

Sobre la base de las recomendaciones del Informe Nolan, la Comisión del Tesoro y de la Función Pública (Treasury and Civil Service Commitee) redactó un Código de Conducta para la Función Púbica (Civil Service Code), acorde con los siete principios de la vida pública formulados por el Informe Nolan, que fueron aceptados por el Gobierno con ligeras modificaciones y publicados en el documento "Avanzando con la continuidad y el cambio" (Taking forward continuity and change) $1995^{14}$.
La Comisión Nolan, que es un comité permanente cuyos miembros son nombrados por tres años, una especie de ataller de ética., da mucha importancia a este Código pues, en su opinión, contribuirá a sostener la moral de la función pública sya que las organizaciones bien motivadas y con confianza en si mismas encuentran mucho más fácil mantener buenos standars de conducta contra sus empleados.

- Que cada organización imparta formación inicial y continua en materia ética.

- Que haya un análisis externo (auditoría pública) que, más allá del análisis financiero, comience a velar por las normas de conducta y los asuntos relativos a la éti$\mathrm{ca}$, incluyendo valoraciones sobre si las decisiones se han tomado correctamente.

En su contexto, dicen FuenteTaja y GUILIÉN, el Informe Nolan viene a significar el aspecto ético de la reforma administrativa, afirmando, por un lado, los principios que deben regir el comportamiento de aquellos que desempeñan cargos públicos (desinterés y correlativa capacidad de asumir el interés público como objetivo; la integridad; la objetividad; la responsabilidad; la transparencia y la capacidad de liderazgo) y, por otro, alentando la adopción de Códigos de Conducta que informen la acruación de los funcionarios públicos y cuya expresión más acabada la constituye el Código de Conducta de la Función Pública (Civil Service Code).

\section{Los valores éticos en el Ante- Proyecto de Ley del Estatuto Básico de la Función Pública}

Como es sabido, el Ministerio de Administraciones Públicas, a través de la Secretaría de Estado para la Administración Pública y de su Dirección General de la Función Pública, viene trabajando en la elaboración de un Anteproyecto de Ley del Estatuto Básico de la Función Pública, que ha sido objeto de numerosas consultas y negociaciones con Administraciones Públicas - Comunidades Autónomas y Federación Espanola de Municipios y Provincias - sindicatos, partidos políticos, profesores universitarios, expertos, etc. Una de las novedades que justamente se ha destacado de este Estatuto ha sido la incorporación de un elenco de valores del servicio público ${ }^{15}$, de inspiración común para todas las personas dependientes de las Administraciones Públicas que trabajen al servicio de los ciudadanos sirviendo con objetividad los intereses generales. 
La incorporación de estos valores éticos al anteproyecto de Estatuto Básico de la Función Pública ha estado precedida, como no podía ser menos, de una reflexión previa sobre el significado y el alcance de la ética en el desempeño del servicio público.

Como destacó el Secretario de Estado para la Administración Pública, Francisco Villar García-Moreno, en su comparecencia ante la Comisión de Régimen de las Administraciones Públicas para informar sobre las lineas básicas del anteproyecto de Ley del Estatuto Básico de la Función Pública, el día 4 de junio de 1997.

"La ética no pretende perseguir comportamientos desviados o irregulares de los funcionarios puiblicos, para lo que ya está el Código Penal o el régimen disciplinario. Su fin es promover la integridad y la buena conducta y dar a los agentes orientaciones sobre la forma en que deben actuar, tomar decisiones y bacer uso de su poder de apreciación en el trabajo cotidiano. No se trata de poner en cuestión la bonestidad y la conducta profesional de los funcionarios públicos, sino que se trata de que con la ética publica se mejoren las competencias, en beneficio propio, de la organización en la que están encuadrados y, en último término, en provecho de la sociedad a la que sirven, señalándoles unos principios, unas orientaciones, asumidos como valores propios de la organización priblica que les guien como puntos de referencia para que puedan adecuar a ellos sus conductas o comportamientos en su actividad profesional babitual. Con la incopporación de estos valores éticos... los hombres y mujeres que componemos la Función Pública veremos reafirmada nuestra función profesional al servicio de los ciudadanos y, a través suyo, las Administraciones Püblicas se verán legitimadas en la gestión objetiva, eficaz y transparente de los asuntos públicos.

Efectivamente, siguiendo con esta línea argumental, ya no es suficiente con que las personas que trabajen en el servicio público se limiten al cumplimiento formal de sus obligaciones, no basta con cubrir, como dice Adela CORTINA, unos mínimos de permanencia en el centro correspondiente y de atención a la clientela, trátese de alumnos, pacientes o de otra suerte de beneficiarios de una actividad profesional, lo que la autora llama funcionarización de las profesiones, sino que las personas que trabajen en el servicio público, como auténticos profesionales, deben aspirar a la excelencia, ya que una profesión no es un oficio ni una simple ocupación. Para conseguir esta aspiración a la excelencia resulta necesario que por parte de las Administraciones Públicas se fomenten "en positivo" aquellos valores que sirvan a quienes trabajan al servicio de los intereses generales como referentes éticos para su superación profesional.

Ciertamente que en la catalogación de los derechos y deberes de los funcionarios que aparece en el proyecto de Estatuto Básico de la Función Pública hay depositados valores éticos que deben regir el comportamiento de los funcionarios, tanto en sus aspectos positivos como negativos. A este propósito, dice MeILÁN Gil que a los funcionarios y también a los ciudadanos les conviene que las faltas de servicio estén tipificadas y que se distingan de las faltas personales así como que las infracciones y sanciones se ajusten al principio de legalidad. Pero seguramente el código coactivo, por detallado que sea, no es el mejor procedimiento para la formación de personas maduras y responsables. A la ley le corresponde tipificar las conductas más claramente desviadas. Pero la responsabilidad va más allá de las directrices que marca la ley; es necesario dar pautas que ayuden a ir construyendo un discurso de la responsabilidad profesional.

En esta línea, cara a la elaboración del Estatuto Básico de la Función Pública sería suficiente de entrada fijar el compromiso por parte de las Administraciones Públicas de desarrollar estrategias que fomenten los valores éticos del servicio público que deben regir la actuación del personal tanto desde el punto de vista interno como en sus relaciones con los ciudadanos. A estos efectos, se hace necesario consignar en el anteproyecto de Ley cuáles son estos "valores éticos del servicio público", que no pueden ser sino el resultado de una interpretación generosa y de una lectura "éticamente sensible del artículo 103.1 de la Constitución Española en cuanto establece los principios a los que deben sujetar su actuación las Administraciones Públicas.

El actual artículo 7 del anteproyecto recoge cuales son estos valores éticos del servicio público: la integridad, la neutralidad, la imparcialidad, la transparencia en la gestión, la receptividad, la responsabilidad profesional y el servicio a los ciudadanos ${ }^{16}$.

Y a continuación añade este mismo artículo que slas Administraciones Prublicas fomentarán modelos de conducta del personal a su servicio que integren los valores éticos del servicio puiblico de su actuación profesional y en sus relaciones con los ciudadanos.

Y ello, porque como dice Agustín IzQuierDo, los fines y los valores sólo alcanzan su sentido en cuanto que son encarnados en una conducta, el único modo en que se hacen verdaderos: "Pues sin tener en cuenta su dimensión práctica, todos los conceptos morales acaban por perder su función propia y más especifica: conducir los actos según una ordenación de valores.

Dado el carácter básico del Estatuto, se ha renunciado, en estos últimos borradores, a diferencia de versiones anteriores, a consignar cuales serían los modelos de conducta o comportamiento "excelente de las personas que trabajan en la Administración Pública, dejando a cada Administración la posibilidad de establecer cuales sean tales modelos, así como libertad para determinar los medios más idóneos para fomentar en positivo estos modelos de conducta inspirados en los valores del servicio público y que no son otros, como hemos visto en epígrafes anteriores, sino el ejemplo de los superiores, la formación ética, los códigos de conducta generales o sectoriales, la consultoría ética, etc.

Debe quedar claro que las conductas o comportamientos inspirados en los valores éticos no son deberes jurídicamente exigibles, 
sino modelos de conducta deseables que las Administraciones Públicas pueden libremente comprometerse a fomentar, $y$, en su caso, compensar a aquellos a quienes los sigan, pero sin que se confunda en ningún caso la ética con el régimen sancionador, penal o disciplinario y sin que se pueda obligar coactivamente a los funcionarios públicos a seguir estos modelos de conducta.

Cabe señalar que los valores éticos del servicio público que habrán de inspirar los modelos de conducta o comportamiento que inspirados en ellos puedan fijar las Administraciones Públicas y que son abomologables con el resto de los países avanzados, como dice el profesor Rodrígufz-ARANA, serán bases del régimen estatutario de los funcionarios públicos, aplicables a todo el personal que trabaja en las Administraciones Públicas, funcionario, laboral, estatutario, en cuanto que son las metas y objetivos que en definitiva se persiguen:

\section{- La mayor profesionalización del personal.}

- La humanización del entorno de trabajo.

- La ayuda para la resolución de los problemas éticos.

- El mejor servicio a los ciudadanos.

- La obtención de perfección y calidad en el trabajo, etc.

Son todos ellos principios universalmente reconocidos en todas las Administraciones Públicas.

Por último, significar que, junto con la aplicación y divulgación de la Ética, el reto planteado es, según RodríGuEz-ARANA, su interiorización por las personas concretas, su ejercicio a través de la cotidianeidad. Porque, como señaló el profesor Aranguren, en el prólogo al estudio de Agustín IZQUIERDO sobre Ética y Administración en relación con la función que tiene la ética pública en la potenciación de lo público, sen la práctica, la forma más poderosa de bacer esa tendencia real es que cada miembro de la burocracia lo baya interiorizado de alguna manera. ${ }^{17}$.
- Funcionario del Cuerpo Superior de Administradores Civiles del Estado.

1 Los periodistas sugieren la redacción de un código de ética para la profesión (de hecho, hay un código de ética periodistica aprobado por el Consejo de Europa); los bancos hablan de un código ético para el buen gobierno de las empresas o la banca; los expertos redactan códigos éticos para los consejos de administración (El Pais, 15.3.98); las autoridades elaboran -códigos de buenas prácticas comerciales para aplicar a proveedores y distribuidores ( $E l$ Mundo, 27.2.98); los políticos piden la elaboración de códigos deontológicos como el recientemente alcanzado para combatir el transfuguismo, denominado -Código de conducta política en relación con el transfuguismo en las corporaciones locales; las más prestigiosas empresas envían a sus ejecutivos a cursos de ética en los centros de mayor prestigio; representantes de 36 colectivos debaten sobre la ética de un millón de profesionales (El Pais, 20.11.1997) y libros de ética, como el de Femando SAvater Ética para Amador, alcanzan los primeros puestos de las listas de ventas.

'Según el profesor, Laureano LóPEz Rodó, los avisos y consejos que nuestros clásicos dan a Reyes y Principes constituyen un curso de doctrina ética que conserva su plena validez para las lacras sociales y politicas de aquella época semejantes a las que advertimos en los políticos de nuestras sociedades contemporáneas. Laureano LOPEZ RODÓ -La ética del Gobernante en nuestros autores del Siglo de Oro, conferencia pronunciada por el autor en la Real Academia de Ciencias Morales y Políticas, el 18 de junio de 1996.

"Adela Cortina, -La ética cívica como ética de mínimos, en Ética Pública y Moral Social. Luis NúNEZZ LADEVĖzE (ed.) Editorial Noesis, Madrid, 1996, pp. 92-93.

' A. MaclNTYRe, Tras la virtud. Crítica, Barcelona, 1987, p. 80.

' Estas nociones de emáximos y múnimos. se inspiran en la tradición del liberalismo político, representada sobre todo por John Rawls y claramente defendida en su libro Political Liberalism. Cambridge University Press, 1993.

" El.término •deontología. (deontologhy) fue inventado en 1825 por Jeremie BENTHAM con el significado de la ciencia de los deberes. BENTHAM consideraba que el témino deontología era más expresivo que el de ética. pero que ambos significaban la misma cosa.

' Ejemplos de este tipo de corrupción son: el sobomo, el tráfico de influencias, el tráfico de información privilegiada, la aceptación de regalos o ventajas, la obtención de puestos futuros, el nepotismo, etc.

s Sobre el fenómeno de la comupción en la vida pública, especialmente en el ámbito iberoamericano, léánse las ponencias contenidas en el libro Ética y Administración
Pública. Documentos del Foro iberoamericano. Isla de Margarita. Venezuela, octubre de 1997, publicado por el Centro Latinoamericano para el Desarrollo (CLAD).

'Pablo García Mexia, ·Reflexiones al hilo del I Congreso Intemacional de Ética Pública. Manifestaciones jurídico-públicas, en Revista de Administración Priblica $n^{2} 136$ (enero-abril 1995).

"' Sobre los códigos de ética dice Victoria Camps que los hay de dos clases: los cenidos a unos pocos valores o principios básicos al estilo de los Diez Mandamientos, como el Informe Nolan, o aquellos más detallados, semejantes a una Ley, que utilizan el método inductivo para extraer de los casos conflictivos aquellas normas de conductas precisas para hacer frente a situaciones similares. Si los primeros tienen el defecto de la imprecisión y de la vaguedad implícita a todo principio ético, los códigos detallados tienen el defecto de confundirse con la ley y tratar de preverlo todo. En cualquier caso, más importante que la amplitud del código es la voluntad de aceptarto por parte de quienes tienen que suscribirlo, así como la creencia de que no es inútil tenerlo.

" El actual Presidente de la Comisión sobre Normas de Conducta en la vida pública es Sir Patrick Neill, de 71 años, educado en Oxford y Juez de profesión, como su antecesor (The Observer, 16.11.97).

12 García de EnterRia se refirió a este informe en su libro Democracia, Jueces y control de la Administración (1995, pp. 76 y ss.). Posteriormente, Jesús Ángel FuENTETAJA Pastor y javier Gullén Carames, completaron su estudio del tema, que incluye amplias referencias a la Administración y Función Pública británica en La regeneración de la Administración Pública en Gran Bretaña (1996). La revista Gestión y Análisis de Politicas Públicas, en su número 5-7, enero-agosto de 1996, también incluye una nota sobre el Informe Nolan (Normas de conducta de la vida pública), del que es autor Manuel MARTíNeZ BARGUENO.

1. Un resumen (summary) de este Informe, que contiene en unas pocas páginas sus principales criterios y recomendaciones, se ha repartido profusamente entre todos los niveles políticos, administrativos, funcionariales, sociales, de comunicación, etc.

"Hay que señalar que la expresión Civil Service Code no hace referencia a lo que en el Derecho continental se entiende por -Código. legislativo. Se trata en este caso de -Códigos de conductar, técnica ésta típicamente anglosajona y que expresa una concepción de autorregulación. que ve grandes ventajas en la disciplina impuesta y vigilada por los propios interesados más que en la abstracta, y sólo excepcionalmente fiscalizable por los Tribunales, impuesta por la legislación (GARCÍA DE ENTERRfa, Democracia, Jueces y control de la Administración, p. 81). 
Is La idea de valor es muy impontante en el ámbito de la Administración Pública ya que supera la noción de deber y afecta inmediatamente a algo relacionado con la moralidad en sí: la voluntad de autorrealizarse como servidor público (RODRiGUEz-ARANA).

1. Compárese esta redacción con las directrices sobre valores éticos sugeridas por Victoria Camps para la elaboración de un código ético para la Función Pública de nuestro país: el servicio al interés general, la imparcialidad y la transparencia, el uso (adecuado) de los bienes priblicos, la responsabilidad profesional, la lealtad a la Administración y la bumanización de la Administración.

Agustin IZQueRDO, Ética y Administración. Instituto Universitario Ortega y Gasset. Papeles de trabajo. Gobierno y Administración Pública.

\section{Bibliografía seleccionada y comentada sobre Ética Pública (en español)}

Decía Jorge Luis BORGES que él se encontraba más orgulloso de los libros que había leído que de los que había escrito. El autor de este artículo se reconoce tributario y fiel intérprete de las apontaciones sobre el estudio de la Ética contenidas en la lista bibliográfica siguiente, cuya consulta recomendamos a los lectores interesados en el teina de la Ética Pública.

\section{Libros}

Centro latinoamericano de adminstración para el Desarrollo (1997), Ética y administración Pública, 178 pp.

Bajo el patrocinio del Centro Latinoamericano de Administración para el Desarrollo se reminio el Foro Iberoamericano sobre Ética y Administración Piblica, promovido por la Secretaria Pro Tempore de la VI Cumbre Iberoamericana de Jefes de Estado y de Gobierno, uno de cuyos ejes convocantes fue el tema -Los valores éticos de la Democracia. El libr recoge las aportaciones de destacados especialistas iberoamericanos en Gobierno y Administración con el comin denominador de esta perspectiva ética.

InstTtuto NaCional de Administración PúBLLCa (1997), Jormadas sobre Ética Priblica. Madrid, 15 y 16 de abril de 1997. Ministerio de Administraciones Públicas. Instituto Nacional de Administración Pública. Madrid, 143 pp.

El libro recoge las aportaciones a las Jomadas sobre Ética Priblica, organizadas por el Instituto Nacional de Administración Pública (INAP) en la primavera de 1997, inailguradas por Lord Nolan y en las que participaron representantes del pensamiento académico: Adela CORTINA, Victoria CAMPS, LOTEnZO MARTIN-RETORTILO y Jaime RODR. GUZZ-ARANA. del mundo parlamentario pentenecientes a todo el arco politico, de las organizaciones intermacionales (OCDE) y altos cargos del Ministerio de Administraciones Piblicas. Cierra el libro un capitulo de conclusiones y una recomendación en forma de declaración final.

Nieto DE ALBA, Ubaldo (1996), Ética del Gobiemo, Economia y comupción. Editorial Complutense, S.A., $88 \mathrm{pp}$.

Nieto GarCiA, Alejandro (1997), Corrupción en la Esparia democrática. Editorial Ariel. Barcelona, 983 pp.

NúNeZ LadEvezze, Luis (ed.) (1996), Ética Píblica y Moral Social. Editorial Noesis. Madrid, $239 \mathrm{pp}$.

El libro recoge las diferentes ponencias expuestas en el curso de la Universidad Complutense sobre Ética Puiblica y Moral Social que, patrocinado por la Fundación Diálogos, se celebró en El Escorial en julio de 1995 y en la que participaron, entre otros, Victoria CaMps y Adela CoRTINA.

OCDE (1997), La ética en el servicio priblico. Colección: Estudios. INAP. Madrid, 140 pp.

Rodriguez-Arava MuNoz, Jaime (1993), Principios de ética priblica ¿comupción o servicio? Editorial Montecorvo, S.A. Madrid, 106 pp.

(Recensión por Manuel Martisez Bargueño, en Revista de Estudios de Administración Local y Autonómica, enero-marzo 1993, pp. 215-217).

__(1996), Ética Institucional. Editorial Dykinson, 297 pp.
(Recensión de Manuel MarTiNez BargueNo, en Revista Aragonesa de Administración Puiblica, $n^{2} 11$, diciembre 1997, pp. 593-601).

SABAN GODOY, Alfonso (1991), El marco jurídico de la comupción. Cuademos Civitas, $103 \mathrm{pp}$.

Análisis riguroso de la comipción desde la perspectiva de la dogmática juridica y en la aplicación práctica de sus esquemas a la vida pública española. Excelente estudio que sobrepasa, pese a su titulo, el ámbito estrictamente juridico para adentrarse en las raices de las convicciones éticas de la sociedad y su traducción en un sistema concreto de relaciones politicas.

Otros libros referidos a la ética en general o a las éticas aplicadas son:

BO:NETE, Enrique (coord.) (1995), Éticas de la Información y Deontologias del Periodismo. Editorial Tecnos. Madrid.

Camps, Victoria (1992), Virtudes Priblicas. Editorial Espasa Calpe. Madrid.

_ (1996), El malestar de la vida pública, Editorial Grijalbo Mondadori. Barcelona.

_y GiNER, Salvador (1998), Mamual de Civismo. Ariel. Barcelona.

_(1998), Hasta un pueblo de demonios. Taurus. Madrid.

CORTINA, Adela (1986), Etica minima. Editorial Tecnos. Madrid.

(1993), Ética aplicada y democracia radical. Editorial Tecnos. Madrid.

_(1994), La ética de la sociedad civil. Editorial Anaya/Alauda. Madrid.

_Conill, Jesús; Domingo, Agustín y Garcia Marzá, Domingo (1994), Ética de la empresa. Editorial Trotta. Madrid.

(1997), -La ética en la sociedad civil. En el libro La corrupción política. Editorial Alianza. Madrid.

_(1997), Ética y legislación de enfermería. Capitulo 6 del libro coordinado por Pilar ARROYO, Mac Graw-Hill. Barcelona.

FERNÁ:DEZZ, José Luis (1994), Ética para empresarios y directivos. ESIC. Madrid.

__ y HORTAL, Augusto (1994), Ética de las profesiones. Universidad Pontificia de Co millas. Madrid.

GraCla, Diego (1988), Fundamentas de Bioética. EUDEMA. Madrid.

Grafo, J. (1993), Diez palabras claves en bioética. V.D. Estella.

LÓPEz AzPTTARTE, E. (1990), Ética y Vida. Ed. Paulinas. Madrid.

LIEDO, Emilio (1994), Memoria de la Ética. Editorial Taurus. Barcelona.

MARINA, José Antonio (1995), Ética para náufragas. Editorial Anagrama. Barcelona. 